\title{
Hubungan antara Literasi Kesehatan Mental, Stigma Diri terhadap Intensi Mencari Bantuan pada Dewasa Awal
}

\author{
NOVIA KARTIKASARI \& ATIKA DIAN ARIANA* \\ Departemen Psikologi Klinis dan Kesehatan Mental, Fakultas Psikologi Universitas Airlangga
}

\begin{abstract}
ABSTRAK
Gangguan mental berkontribusi pada peningkatan beban sakit dunia, resiko yang besar salah satunya dimiliki oleh usia dewasa awal. Akibat adanya faktor hambatan, seseorang memilih untuk tidak mencari bantuan pada profesional. Tujuan penelitian ini adalah mengetahui hubungan antara literasi kesehatan mental dan stigma diri terhadap intensi mencari bantuan pada dewasa awal. Penelitian ini menggunakan metode survei dan purposive sampling. Melibatkan 571 responden dewasa awal (berusia 18-29 tahun), asesmen dilakukan menggunakan skala intensi mencari bantuan, skala literasi kesehatan mental dan skala stigma diri terkait pencarian bantuan. Hasil menunjukkan bahwa literasi kesehatan mental berkorelasi positif dengan intensi mencari bantuan, stigma diri berkorelasi negatif dengan intensi mencari bantuan, stigma diri berkorelasi negatif dengan literasi kesehatan mental. Penelitian ini menyimpulkan bahwa seorang dewasa awal yang memiliki literasi kesehatan mental yang baik memiliki kecenderungan stigma diri yang rendah dan tingkat intensi mencari bantuan yang tinggi.
\end{abstract}

Kata kunci: intensi mencari bantuan, literasi kesehatan mental, stigma diri, dewasa awal

\begin{abstract}
Mental illness had contributed towards global burden of disease. One of the populations with highest risk of mental illness is young adult. Someone does not seek for a mental health professional because of many barriers. This study aimed to find out about the correlation of mental health literacy, selfstigma and help-seeking intention among young people. Conducted using survey and purposive sampling which involved 571 young adults (between 18-29 years). They were assesed using mental help-seeking intension scale, mental health knowledge schedule and self-stigma of seeking-help. The result showed that mental health literacy were positively associated with help-seeking intention, selfstigma were negatively correlated with help-seeking intention, mental health literacy were negatively correlated with self-stigma. This study concluded that young people who well literate in mental health issue, tend to have a low level of self-stigma and high help-seeking intention professional help.
\end{abstract}

Key words: help-seeking intention, mental health literacy, self-stigma, young adult 
INSAN Jurnal Psikologi dan Kesehatan Mental, 2019, Vol. 4(2), 64-75, doi: 10.20473/jpkm.v4i22019.64-75 Dikirimkan: 16 Oktober 2019 Diterima: 10 Desember 2019 Diterbitkan: 27 Februari 2020

Editor: Rizqy Amelia Zein

*Alamat korespondensi: Fakultas Psikologi Universitas Airlangga, Jalan Airlangga 4-6 Surabaya 60286. Posel: atika.ariana@psikologi.unair.ac.id

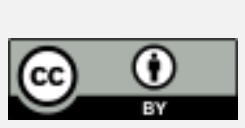

Naskah ini merupakan naskah dengan akses terbuka dibawah ketentuan the Creative Common Attribution License (http://creativecommons.org/licenses/by/4.0), sehingga penggunaan, distribusi, reproduksi dalam media apapun atas artikel ini tidak dibatasi, selama sumber aslinya disitir dengan baik.

\section{PE N D A H U L U A N}

Laporan yang dirilis oleh Badan Organisasi Kesehatan Dunia mengungkapkan bahwa di era tahun 2000-an ini, ada satu diantara empat orang di dunia pernah atau mempunyai resiko mengalami gangguan kesehatan mental atau neurologis dalam rentang kehidupannya. Artinya ada sekitar 450 juta manusia saat ini yang diprediksi akan memiliki kondisi kesehatan mental yang tidak baik dan beresiko mengalami disabilitas karena adanya gangguan jiwa yang dialaminya (McBain, Salhi, Morris, Salomon, \& Betancourt, 2012).

Usia dewasa awal dianggap memiliki resiko yang besar untuk terkena gangguan mental. Hal ini karena pada tahap ini merupakan tahap peralihan dari masa remaja yang masih bergantung kepada orangtua menuju dewasa yang independen, masa ini diangap penuh dengan ketidakstabilan. Menurut Arnett, Zakauskiene dan Sugimura (2014) dewasa awal belum memiliki struktur kehidupan yang stabil, sering bergonta-ganti pekerjaan maupun kehidupan percintaan adalah salah satu penyebabnya sebelum akhirnya seorang dewasa awal membuat keputusan komitmen jangka panjang atas kehidupannya.

Berdasarkan dari data review epidemiologis di Amerika 2008, lebih dari 40\% prevalensi beberapa gangguan jiwa selama 12 bulan terjadi pada usia 18-29 tahun. Angka ini lebih tinggi dari kelompok di rentang usia lain. Khususnya pada gangguan kecemasan, mood dan penyalahgunaan obat-obatan. Hal yang sama ditemukan di Jepang berdasarkan survei epidemiologis nasional 2005 menemukan gangguan kecemasan dan mood merupakan gangguan kejiwaan paling banyak ditemukan pada orang di usia 20-34 tahun, lebih tinggi dari dewasa usia 35 tahun atau lebih (Arnett, Žukauskienė, \& Sugimura, 2014).

Seseorang yang kesehatan mentalnya terganggu bisa mengalami kondisi disabilitas atau kecacatan di hidupnya karena gangguan jiwa umumnya akan mengakibatkan kondisi disabilitas bagi penderitanya dibandingkan mengarahkan pada kematian dini (WHO, 2001). Global Burden of Disease untuk gangguan mental dan neurologis yang dihitung dari tahun 1990 hingga 2010 menunjukkan adanya peningkatan dengan jumlah sebanyak 37.6\%. DALY (Disability-Adjusted Life Year) juga meningkat dari 5.4\% di tahun 1990 jadi 7.4\% di tahun 2010. Satu DALY dianggap sebagai hilangnya satu tahun hidup "sehat" seseorang (Vos, Flaxman \& Naghavi, 2012; Murray, Vos \& Lozano, 2012 dalam Whiteford, dkk., 2013).

Data Riskesdas (2013) menyebutkan gangguan jiwa berat ada sebanyak 1,7 per mil dengan sebaran terbanyak di DI Yogyakarta, Aceh, Sulawesi Selatan, Bali, dan Jawa Tengah. Data proporsi penderita gangguan jiwa secara keseluruhan berdasarkan data Riskesdas tahun 2018 pun mengalami kenaikan yang cukup signifikan jika dibandingkan dengan data Riskesdas 2013, naik dari 1,7\% menjadi 7\% (Kemenkes, 2018). 
Data Ikatan Psikolog Klinis Indonesia mencatat terdapat 1648 psikolog klinis dengan 1050 orang yang terverifikasi di IPK. IPK menyebutkan per-maret 2019 hanya ada 71 psikolog klinis yang bekerja di Puskesmas. Kemudian untuk jumlah psikiater yang diperoleh dari data paling baru dirilis oleh Departemen Kesehatan di tahun 2010 lalu, berjumlah kurang lebih 600 tenaga Psikiater yang ada di seluruh Indonesia. Psikiater dan psikolog yang ada saat ini secara keseluruhan masih banyak yang terkonsentrasi di kawasan kota dan khusus di Indonesia sendiri terkonsentrasi di Pulau Jawa. Tenaga kesehatan yang ada belum mampu diperbantukan untuk menutup kekurangan profesional kesehatan mental khususnya untuk layanan kesehatan primer seperti puskesmas. Akibatnya penderita gangguan mental tidak terakomodasi secara keseluruhan. Afifah (2016) menemukan bahwa kemampuan tenaga kesehatan di puskesmas dalam mengenali gangguan mental tergolong rendah meski begitu sebenarnya mereka sudah memiliki pengetahuan kesehatan mental hanya saja belum mampu mengimplementasikannya. Fokus kesehatan yang ada di puskesmas Indonesia saat ini memang masih berkisar pada penanganan kesehatan fisik.

Untuk mendorong masyarakat yang memiliki kesadaran baik mengenai kesehatan mental juga sangat bergantung pada perilaku individu masyrakatnya, perilaku mencari bantuan dalam konteks kesehatan mental didefinisikan sebagai suatu proses koping adaptif yang bertujuan untuk mencari pendampingan dari luar untuk menyelesaikan masalah terkait kesehatan mental seseorang (Rickwood, Thomas, \& Bradford, 2012). Perilaku mencari bantuan ini penting untuk mengeksplorasi dan memahami mengapa seorang pasien lebih memilih untuk menunda atau malah mendorong tindakan lain terkait dengan kondisi kesehatannya.

Marthoenis, Aichberger dan Schouler-Ocak (2016) di Provinsi Aceh dan Marchira dan kawan-kawan (2016) di Provinsi Daerah Istimewa Yogyakarta menemukan adanya pola pencarian bantuan yang khas pada masyarakat Indonesia, dimana pasien dan keluarga akan mengunjungi penyembuh tradisional dulu selama beberapa kali sebelum akhirnya pergi ke profesional kesehatan mental ketika dirasa pasien tidak mengalami perubahan. Terdapat juga kasus dimana orang dengan psikosis masuk perawatan medis dengan relatif cepat, namun dengan cepat juga mereka berhenti menjalaninya (umumnya, berhenti dari perawatan medis), meski tidak diketahui apakah pengobatannya terselesaikan atau tidak. Keterlambatan penanganan yang terjadi akibat adanya penundaan pencarian bantuan profesional atau malah tidak mencari bantuan sama sekali bisa berdampak pada semakin parahnya suatu gangguan yang diderita seseorang.

Seseorang juga mungkin untuk memilih tidak mencari bantuan akibat tidak mau menanggung rasa malu jika diketahui bahwa dia memiliki kekhawatiran pada kesehatan mentalnya atau terkena label bahwa dia menderita gangguan mental. Usia dewasa awal memiliki keharusan mengenai beberapa hal fundamental yang harus ada pada dirinya seperti lingkaran lingkungan yang aman, harga diri yang diperoleh dari penghargaan orang laindan kecenderungan untuk menunjukkan pada orang disekitarnya bahwa dirinya memiliki kontrol atas kehidupannya. Seorang dewasa awal merasa harus jadi individu yang reliabel dan dapat diandalkan, sehingga akan merasa malu jika dilihat tidak mampu oleh orang disekitarnya, karenanya ada kecenderungan penolakan pada bantuan di luar dirinya (Mitchell, 2017).

Intensi mencari bantuan memprediksi seberapa mungkin perilaku mencari bantuan tersebut dilakukan di masa depan oleh seseorang. Intensi adalah faktor paling dekat yang menjadi pembentuk suatu perilaku (Ajzen, 1991). Seseorang yang memiliki kekhawatiran pada kesehatan mentalnya baik itu yang sudah merealisasikan perilaku mencari bantuan maupun yang sudah memiliki niat namun belum direalisasikan melalui perilaku. Dimana asumsinya kedua kelompok ini memiliki intensi yang lebih tinggi dibandingkan mereka yang tidak memiliki kekhawatiran dan ingin mencari bantuan di luar dirinya. Menurut Marthoenis, Aichberger dan Schouler-Ocak (2016) dan Marchira

INSAN Jurnal Psikologi dan Kesehatan Mental

Tahun 2019, Vol. 4(2), 64-75

doi: 10.20473/jpkm.v4i22019.64-75 
dan kawan-kawan (2016) perilaku mencari bantuan memiliki beberapa faktor hambatan sosial khususnya pada konteks masyarakat di Indonesia, faktor kepercayaan yang menyimpang mengenai penyebab gangguan kesehatan mental (karena kekuatan spiritual), masyarakat lebih memilih berobat pada penyembuh tradisional (seperti paranormal/dukun, kyai, dan ustadz) sebelum mencari bantuan pada profesional kesehatan mental. Kepercayaan semacam ini secara frekuen ditemui di negaranegara berkembang. Terakhir adalah kepercayaan keluarga yang berpengaruh pada keputusan keluarga dalam menentukan pengobatan pasien (sangat terkait dengan keadaan finansial keluarga, sikap dan kepercayaan keluarga terhadap gangguan mental tersebut, dst.).

Stigma sosial yang kuat mengenai gangguan mental membuat keluarga maupun pasien menjadi ragu ke profesional karena takut di label macam-macam. Kelompok yang terkena stigma adalah kelompok yang biasanya memiliki status rendah atau kekuatan yang kecil di masyarakat, dan sangat sulit bagi mereka untuk menghindari label negatif yang diciptakan masyarakat untuk mereka (Hogg \& Vaughan, 2011). Stigma sosial tidak berhenti hingga disitu. Orang-orang yang merasa dirinya berada dalam kelompok yang terstigma memiliki kecenderungan lebih besar untuk menginternalisasi evaluasi ini dan membentuk gambaran diri yang negatif yang ditandai adanya penurunan harga diri seseorang (Hogg \& Vaughan, 2011). Stigma diri yang muncul karena perilaku mencari bantuan adalah suatu proses penurunan harga diri (self-esteem) yang muncul ketika seseorang melakukan perilaku mencari bantuan profesional, dimana dia beranggapan bahwa dengan melakukan hal tesebut kehormatan dirinya akan turun, termasuk perasaan puas pada dirinya, kepercayaan diri akan kemampuannya, dan keseluruhan harga dirinya sebagai seorang individu akan berkurang (Vogel, Wade, \& Haake, 2006).

Munculnya beberapa permasalahan sosial terkait kepercayaan yang salah mengenai penyebab gangguan mental, stigma yang tinggi hingga persepsi yang kurang tepat mengenai kesehatan mental adalah karena tingkat pengetahuan mengenai gangguan mental yang ada di masyarakat kurang untuk mengenali gangguan mental dan memahaminya, diperburuk dengan gejala awal dari suatu gangguan mental yang seringkali tidak terlihat dan mampu dikenali oleh sebagian besar orang (Reavley \& Jorm, 2011). Secara lebih spesifik stigma terbentuk karena adanya ketidakpedulian (ignorance) seseorang, yang kemudian menjadi prasangka (prejudice) dan akhirnya menjadi diskriminasi (discrimination) (Thornicroft, Rose, Kassam, \& Sartorius, 2007). Permasalahan adanya ketidaktahuan (ignorance) seseorang ini sangat berkaitan dengan adanya masalah pada tingkat pengetahuan (knowledge) seseorang. Rendahnya pengetahuan mengenai isu kesehatan mental berkaitan dengan rendahnya kemampuan seseorang dalam mengenali gejala, memunculkan kepercayaan yang salah (false belief) dan persepsi negatif seseorang mengenai hal-hal terkait dengan kesehatan mental, hal ini akan berdampak pula pada pola pencarian bantuan seseorang ketika dirinya menemui masalah terkait dengan gangguan kesehatan mental pada dirinya sendiri maupun pada orang lain (Pheh, dkk., 2018).

Pengetahuan mengenai kesehatan mental seseorang disebut juga dengan istilah literasi kesehatan mental (Crisp, dkk., 2005 dalam Thornicroft, Rose, Kassam \& Sartorius, 2007). Evans-Lacko dan kawan-kawan (2010) mendefinisikan literasi kesehatan mental sebagai suatu pengetahuan terkait kesehatan mental, yang mencakup didalamnya pengetahuan mengenai efikasi perawatan, kesadaran, pencarian bantuan dan pekerjaan yang berpengaruh pada penurunan stigma serta peningkatan sikap dan perilaku seseorang terkait kesehatan mental. Literasi kesehatan mental dan stigma diri dianggap memiliki kaitan yang erat dalam memunculkan perilaku mencari bantuan pada individu. Stigma diri berkaitan dengan perilaku mencari bantuan seseorang pada layanan kesehatan mental (Milin, dkk. 2016 dalam Cheng, dkk., 2018) dalam penelitiannya menemukan bahwa ketika literasi kesehatan mental siswa diperkuat, pandangan stigmatis mereka mengenai gangguan mental juga cenderung menurun. 
Kemudian ditemukan hubungan antara literasi kesehatan mental, stigma diri dan sikap terhadap perilaku mencari bantuan oleh Cheng dan kawan-kawan (2018) pada 1535 responden mahasiswa di Amerika. Menemukan bahwa literasi kesehatan mental mampu memprediksi sikap terhadap perilaku mencari bantuan dan stigma diri seseorang pada layanan kesehatan mental. Dimana literasi kesehatan mental yang tinggi akan sejalan dengan sikap terhadap perilaku mencari bantuan yang tinggi pula dan stigma diri yang cenderung rendah. Berdasarkan kajian literatur dari penelitian sebelumnya, hipotesis penelitian ini adalah literasi kesehatan mental dan stigma diri berhubungan secara signifikan terhadap intensi mencari bantuan pada dewasa awal di Indonesia. Adapun tujuan dari penelitian ini adalah mengetahui ada tidaknya korelasi beberapa faktor pendorong intensi mencari bantuan (literasi kesehatan mental dan stigma diri) pada dewasa awal di Indonesia.

\section{E T O D E}

\section{Partisipan}

Penelitian ini menggunakan pendekatan kuantitatif dengan desain penelitian menggunakan metode survei. Total responden penelitian berpartisipasi dalam penelitian ini adalah sebanyak 571 orang dan tersebar cukup luas dari berbagai daerah di Indonesia. Kriteria responden terdiri dari: a.) merupakan warga negara indonesia; dan b.) berusia antara 18-29 tahun. Adapun penelitian ini menggunakan tiga instrumen yang dua diantaranya telah melalui proses terjemahan dari skala penelitian aslinya dan satu lainnya menggunakan versi yang sudah di terjemahkan oleh peneliti sebelumnya kedalam bahasa Indonesia.

\section{Prosedur}

Pengambilan data dilakukan pada tanggal 13 Mei 2019 hingga tanggal 19 Mei 2019. Pengambilan data dilakukan secara online dengan menggunakan kuesioner online Google Forms yang disebarkan di berbagai media sosial agar kuesioner bisa dengan mudah disebar maupun diakses oleh responden dari berbagai wilayah. Total responden yang berpartisipasi selama penelitian ini adalah 571 orang dewasa awal.

\section{Pengukuran}

Skala intensi mencari bantuan diterjemahkan dari Mental Health Intention Scale (MHSIS) yang dikembangkan oleh Hammer \& Spiker (2018). Skala ini mengukur kecenderungan seseorang untuk mencari bantuan pada profesional kesehatan mental ketika dirinya mengalami kekhawatiran pada kesehatan mentalnya. Format skala ini adalah Likert dengan tujuh alternatif jawaban (sangat tidak mungkin/benar/setuju, tidak mungkin/benar/setuju, agak tidak mungkin/benar/setuju, netral, agak mungkin/benar/setuju, mungkin/benar/setuju dan sangat mungkin/benar/setuju). Jumlah aitem yang digunakan dalam penelitian adalah tiga aitem dengan nilai reliabilitas sebesar 0,919.

Skala literasi kesehatan mental diterjemahkan dari Mental Health Knowledge Schedule (MAKS) yang dikembangkan oleh Evans-lacko, dkk. (2010). Skala ini mengukur pengetahuan terkait kesehatan mental yang ranahnya berhubungan dengan stigma pada kesehatan mental dan komponennya. Format skala ini adalah Likert dengan lima alternatif jawaban (sangat setuju, setuju, tidak tahu/netral, tidak setuju dan sangat tidak setuju). Jumlah aitem yang digunakan dalam penelitian adalah enam aitem dengan nilai reliabilitas sebesar 0,366. Adapun tidak tingginya skor reliabilitas MAKS telah dijelaskan oleh Evans-lacko dan kawan-kawan (2010) yang mengungkapkan bahwa tidak tingginya reliabilitas 
internal konsistensi alat ukur MAKS sangat wajar terjadi, hal ini karena MAKS tidak dikembangkan sebagai sebuah skala sehingga konsistensi internal tidak terlalu diperhatikan, Evans-lacko dan kawankawan (2010) memutuskan untuk tidak menyingkirkan aitem berdasarkan rendahnya skor alpha. Selain itu MAKS juga dikembangkan dari struktur pertanyaan multi-dimensi yang bertujuan untuk menguji berbagai tipe pengetahuan terkait gangguan mental. MAKS juga dikembangkan untuk mengukur kelompok aitem heterogen sehingga konsistensi internal yang tinggi tidak terlalu diprediksikan, hal ini dikarenakan seorang responden mungkin memiliki skor yang tinggi di satu area pengetahuan namun sangat mungkin disaat yang bersamaan responden tersebut tidak memiliki pengetahuan yang baik pada area yang lain (Evans-lacko, dkk., 2010).

Skala stigma diri yang digunakan adalah Self-Stigma of Seeking Help (SSOSH) dikembangkan oleh Vogel, Wade \& Haake (2006) yang sudah diterjemahkan kedalam versi bahasa indonesia oleh Soebiantoro (2017). Skala ini mengukur stigma diri yang muncul ketika seseorang hendak melakukan perilaku mencari bantuan. Format skala ini adalah Likert dengan lima alternatif jawaban (sangat setuju, setuju, netral, tidak setuju dan sangat tidak setuju). Jumlah aitem yang digunakan dalam penelitian adalah sepuluh aitem dengan nilai reliabilitas sebesar 0,687.

\section{Analisis data}

Uji asumsi yang digunakan dalam penelitian ini adalah uji normalitas dan linearitas. Analisis korelasi yang digunakan dalam penelitian ini adalah analisis korelasi Spearman's rho.

\section{HAS IL P EN ELIT IAN}

Berdasarkan hasil analisis uji korelasi antara intensi mencari bantuan dengan literasi kesehatan mental memiliki korelasi $(\rho(571)=0.19, p<0.001)$. Variabel intensi mencari bantuan dengan stigma diri juga menunjukkan adanya korelasi $(\rho(571)=-0.39, p<0.001)$ Hasil ini mengindikasikan semakin tinggi tingkat stigma diri seseorang maka semakin rendah tingkat intensi mencari bantuannya, dan hal ini berlaku sebaliknya.

Literasi kesehatan mental dan stigma diri memiliki korelasi yang lemah $(\rho(571)=-0.18, p<0.001)$ Hasil analisis uji korelasi berganda yang dilakukan antara variabel literasi kesehatan mental, stigma diri terhadap intensi mencari bantuan mengindikasikan adanya hubungan yang cukup bermakna $(\rho(571)=0.41, p<0.001)$

\section{I S K U S I}

Hasil analisis statistik dalam penelitian ini menunjukkan bahwa literasi kesehatan mental dan stigma diri secara bersama-sama berhubungan dengan intensi mencari bantuan. Hal ini mengindikasikan terdapat hubungan yang cukup signifikan antara literasi kesehatan mental dan stigma diri dengan intensi mencari bantuan. Mendukung penelitian sebelumnya dilakukan oleh Cheng dan kawan-kawan (2018) pada 1535 mahasiswa yang menemukan bahwa stigma diri dan literasi kesehatan mental secara signifikan dan unik menjelaskan sikap terhadap perilaku mencari bantuan seseorang. Cheng dan kawan-kawan (2018) menemukan bahwa mahasiswa yang memiliki stigma diri lebih cenderung kurang dalam menunjukkan sikap penerimaan terhadap pencarian bantuan profesional psikologis. Kemudian mahasiswa yang mampu mengenali gangguan kecemasan umum (general anxiety disorder) cenderung memiliki pandangan yang positif terhadap pencarian bantuan profesional psikologis. Literasi kesehatan mental dan intensi mencari bantuan memiliki hubungan yang positif dimana semakin seseorang memiliki pengetahuan mengenai kesehatan mental semakin dia 
memandang dan percaya bahwa perilaku mencari bantuan sebagai sesuatu hal yang positif, dan berlaku pula sebaliknya.

Hasil analisis statistik menunjukkan terdapat hubungan yang positif pada variabel intensi mencari bantuan dan literasi kesehatan mental, hal ini mengindikasikan seseorang yang memiliki literasi kesehatan mental baik/tinggi berarti ia memiliki pengetahuan mengenai efikasi perawatan gangguan mental yang baik, kesadaran mengenai pentingnya kesehatan mental, mengetahui sumber pencarian bantuan yang tepat ketika mengalami gangguan psikologis, dan mengetahui pekerjaan-pekerjaan yang terkait dengan perawatan kesehatan mental, dimana pandangan stigmatisasi seseorang cenderung turun mengenai hal-hal terkait gangguan mental (Evans-lacko, dkk., 2010). Dengan memiliki pemahaman yang baik mengenai berbagai hal terkait kesehatan mental, seseorang yang merasa dirinya mengalami permasalahan atau kekhawatiran terkait kesehatan mentalnya akan memiliki niat atau kesiapan untuk mencari pendampingan profesional di luar dirinya (Hammer \& Spiker, 2018).

Temuan ini mendukung penelitian yang telah dilakukan sebelumnya, Rafal, Gato \& Debate (2018) menemukan tingkat literasi kesehatan mental yang rendah, pengetahuan kesehatan mental yang terbatas, kepercayaan mengenai kesehatan mental yang lemah, sikap terhadap kesehatan mental buruk, tingginya stigma diri untuk mencari bantuan secara signifikan berdampak pada tingkat kepercayaan diri seseorang untuk mencari bantuan, akibatnya intensi mahasiswa untuk mencari bantuan profesional menjadi rendah. Marchira dan kawan-kawan (2016) mengatakan salah satu faktor penghambat perilaku tersebut adalah karena adanya misinformasi masyarakat mengenai suatu gangguan mental dan terlambatnya kemampuan menyadari gejala suatu gangguan mental, hal ini mengakibatkan suatu hambatan dalam perilaku mencari bantuan. Kelly dan kawan-kawan (2007 dalam Evans-lacko, dkk., 2010) membenarkan hal ini dimana pengetahuan secara spesifik membentuk kemampuan seseorang untuk mengenal gejala gangguan mental dimana hal ini mungkin menfasilitasi perilaku mencari bantuan itu sendiri dan seseorang menjadi lebih memahami ketika berbicara dengan seorang tenaga profesional kesehatan mental mengenai isu tersebut.

Hasil analisis statistik menunjukkan bahwa terdapat hubungan yang negatif antara stigma diri dengan intensi mencari bantuan. Mengindikasikan bahwa seseorang yang memiliki stigma diri yang tinggi maka ia mengalami pengurangan harga diri mulai muncul ketika seseorang hendak atau sudah mencaribantuan psikologis pada layanan kesehatan mental. Hal ini dikarenakan pencarian bantuan diluar diri seseorang dan gangguan mental cenderung di internalisasikan oleh seseorang sebagai suatu bentuk inferioritas atau inadekuasi diri (Vogel, Wade, \& Haake, 2006). Seseorang yang merasa bahwa mencari bantuan semakin memperparah inferiorioritasnya ketika ia mengalami permasalahan atau kekhawatiran terkait kesehatan mentalnya dia tidak akan lebih memiliki niat atau kesiapan untuk mencari pendampingan profesional di luar dirinya (Hammer \& Spiker, 2018)

Hal ini juga terkait dengan kecenderungan dari dewasa awal yang ingin selalu menunjukkan bahwa dia memiliki kontrol atas kehidupannya serta dipandang reliabel dan bisa berdiri sendiri (Mitchell, 2017). Akibatnya meskipun seorang dewasa awal yang merasa khawatir pada keadaan psikologisnya, ia cenderung memilih untuk tidak mencari bantuan karena bisa memperburuk perasaan inferioritas atas dirinya. Temuan ini sejalan dengan beberapa penelitian mengenai stigma diri yang dikaitkan dengan perilaku mencari bantuan. Vogel, Wade dan Haake (2006) menemukan bahwa seseorang yang memiliki stigma diri yang tinggi cenderung memiliki sikap yang negatif pada pelayanan perawatan, temuan ini juga mengusulkan bahwa stigma diri yang dikaitkan dengan pencarian bantuan psikologis ini mungkin menjadi faktor penghambat dalam keputusan pencarian bantuan. Vogel, Shecthman dan Wade (2010) juga menemukan bahwa stigma sosial yang diinternalisasi menjadi stigma diri berkorelasi secara negatif dengan sikap seseorang terhadap grup konseling, stigma sosial dan stigma 
diri. Pheko, Chilisa, Balogun dan Kgathi (2013) juga menemukan bahwa stigma diri dan stigma sosial dalam mencari bantuan secara negatif berkorelasi dengan intensi mencari bantuan itu sendiri.

Hasil analisis statistik menunjukkan bahwa terdapat hubungan yang negatif antara literasi kesehatan mental dengan stigma diri. Menunjukkan bahwa seseorang yang memiliki literasi kesehatan mental baik atau tinggi pandangan stigmatisasinya cenderung turun mengenai hal-hal terkait gangguan mental (Evans-lacko, dkk., 2010), ia juga tidak lebih mudah mensetujui hal-hal stigmatisasi diluar dirinya sehingga seseorang tidak mudah menginternalisasinya dengan kata lain dia tidak memiliki stigma diri yang tinggi (Vogel, Shechtman, \& Wade, 2010)

Temuan ini mendukung penelitian sebelumnya, penelitian Cheng dan kawan-kawan (2018) yang menunjukkan adanya hubungan negatif dimana stigma diri akan menurun ketika literasi kesehatan mental naik. Crowe, Mullen \& Littlewood (2018) juga menemukan adanya hubungan negatif dan signifikan antara stigma diri dan literasi kesehatan mental. Temuan ini mengindikasikan bahwa stigma diri baik itu dalam hal terkait mencari bantuan atau gangguan mental sama-sama merupakan prediktor yang penting dalam literasi kesehatan mental. Stigma diri pada dasarnya adalah proses kelanjutan dari stigma sosial, dimana stigma sosial yang diinternalisasi oleh seseorang dan mengalami persetujuan, kemudian mulai diaplikasikan pada diri sendiri dan akan mengalami penurunan selfesteem (Watson, Corrigan, Larson, \& Sells, 2007). Stigma diri dan stigma sosial pada prosesnya tidak dapat dipisahkan.

Rendahnya tingkat literasi kesehatan mental seseorang dianggap sebagai sebuah anteseden munculnya stigma. Stigma pada dasarnya terbentuk karena adanya ketidaktahuan seseorang (ignorance) yang kemudian memunculkan prasangka (prejudice) dan menjadi diskriminasi (discrimination), ketidaktahuan ini muncul karena dasar permasalahan pada pengetahuan seseorang (Thornicroft, Rose, Kassam, \& Sartorius, 2007). Namun tidak hanya sebagai anteseden saja tingkat literasi kesehatan mental yang tinggi dianggap sebagai sebuah faktor protektif seseorang untuk mengurangi stigma, dalam jurnal Crowe, Mullen \& Littlewood (2018) disebutkan bahwa hubungan keduanya adalah inverse (saling berbalik). Literasi kesehatan mental di sisi lain dijelaskan sebagai sebuah faktor protektif yang penting dimiliki seseorang untuk menumbuhkan kesadaran adanya suatu gangguan kesehatan mental, menumbuhkan keinginan untuk pergi ke layanan kesehatan, dan mempelajari kemampuan untuk mendukung orang orang yang mengalami isu kesehatan mental.

Rendahnya pengetahuan mengenai kesehatan mental akan berdampak pada munculnya persepsi negatif dan kepercayaan yang tidak tepat mengenai kesehatan mental, hal ini akan berdampak pula pada cara seseorang memandang isu kesehatan mental (secara positif atau negatif) dan bahkan membuat keputusan untuk mencari perawatan ketika dirinya menemui suatu masalah terkait kesehatan mental (Pheh, dkk., 2018). Stigma diri yang tinggi diasosiasikan dengan rendahnya sikap terhadap pencarian bantuan.

Adapun keterbatasan dalam penelitian ini meliputi tiga hal yakni proses pengambilan data penelitian dan pertimbangan terkait adaptasi salah satu ukur. Pada poin yang pertama terkait proses pengambilan data, dengan pertimbangan pemilihan populasi yang cukup luas membuat peneliti memutuskan untuk melakukan pengambilan data melalui kuesioner online agar data bisa tersebar luas, namun pengisian data melalui kuesioner online sangat beresiko terhadap adanya pemalsuan (baik itu pada data identitas ataupun jawaban responden) hal ini dikarenakan peneliti tidak bisa hadir untuk melihat dan mengecek langsung data yang diisi responden. Kemudian penyebaran data melalui kuesioner online google form membuat tidak semua masyarakat mampu menjangkau dan bersedia untuk mengisi kuesioner penelitian, khususnya untuk mereka yang kurang fasih dengan teknologi atau tidak familiar dengan internet akan sangat mungkin menemui kesulitan (baik dalam akses maupun 
saat pengisian).

Pada poin kedua terkait pertimbangan untuk melakukan adaptasi pada salah satu ukur, dalam hal ini adalah pada skala literasi kesehatan mental yang digunakan yakni MAKS. Alat ukur MAKS dalam proses pembuatannya memang tidak terlalu memperhatikan reliabilitas internal konsistensi, karena MAKS tidak dikembangkan sebagai sebuah skala sehingga konsistensi internalnya tidak terlalu diperhatikan, kemudian seseorang bisa memiliki pengetahuan di satu hal namun belum tentu memiliki pengetahuan yang baik di hal lain (Evans-lacko, dkk., 2010), sehingga dalam penelitian ini didapatkan reliabilitas alpha cronbach yang kurang memuaskan. Namun meskipun alasan ini dibenarkan oleh peneliti asli, jika peneliti selanjutnya ingin memperbaiki reliabilitas MAKS dengan disesuaikan pada konteks masyarakat Indonesia bisa dilakukan proses lebih lanjut yakni proses adaptasi alat ukur kemudian melakukan test-retest selama beberapa kali hingga dirasa didapatkan hasil yang memuaskan, karena penulis dalam penelitian ini hanya melakukan proses translasi alat ukur saja dan menggunakan uji terpakai.

\section{S I M P U L A N}

Berdasarkan hasil penelitian ini dapat disimpulkan bahwa terdapat hubungan positif dan signifikan antara literasi kesehatan mental dan intensi mencari bantuan pada dewasa awal, yang artinya semakin tinggi literasi kesehatan mentalnya, maka semakin tinggi intensi mencari bantuan yang dimiliki oleh seorang dewasa awal. Kemudian terdapat hubungan negatif dan signifikan antara stigma diri dan intensi mencari bantuan pada dewasa awal, yang artinya semakin tinggi stigma diri, maka semakin rendah intensi mencari bantuan yang dimiliki oleh dewasa awal. Dan yang terakhir terdapat hubungan negatif antara literasi kesehatan mental dan stigma diri pada dewasa awal, yang artinya semakin tinggi tingkat literasi kesehatan mental seseorang, maka semakin stigma diri yang dimiliki oleh dewasa awal.

Saran

Sejalan dengan hasil penelitian yang diperoleh, maka dapat diajukan beberapa saran. Saran untuk penelitian berikutnya apabila ingin melakukan penelitian dengan topik yang sama, diharapkan untuk memperluas kajian teoritik mengenai topik perilaku mencari bantuan, stigma diri dan literasi kesehatan mental yang disesuaikan dengan konteks masyarakat Indonesia yang khas. Penelitian selanjutnya perlu mempertimbangkan faktor-faktor lain yang tidak diteliti atau digali didalam penelitian ini untuk dimasukkan kedalam penelitiannya dan memperkaya khazanah ilmu, serta mengetahui faktor yang mungkin lebih berpengaruh dalam perilaku mencari bantuan pada masyarakat di Indonesia. Penelitian selanjutnya perlu mempertimbangkan untuk melakukan survei besar dan longitudal untuk mendapatkan hasil yang lebih representatif dikarenakan penelitian ini dirasa masih kurang representatif dalam menggambarkan populasi dewasa awal secara luas di Indonesia, penelitian selanjutnya juga perlu membandingkan karakteristik demografi tertentu untuk mengetahui ada tidaknya perbedaan antara ketiga variabel ini pada faktor demografi yang berbeda.

Saran untuk pemangku kepentingan, pemerintah diharapkan menaruh perhatian dan menggalakkan upaya promosi kesehatan mental khususnya pada tahap usia beresiko seperti dewasa awal. Diharapkan juga melalui penelitian ini, pemerintah lebih gencar lagi dalam mempromosikan kesadaran akan kesehatan mental melalui cara-cara yang lebih efektif secara metodologi, karena sudah diuji di sebuah penelitian, sehingga bisa semakin meningkatkan keberhasilan upaya promosi. Kemudian pemberian pendidikan mengenai kesehatan mental melalui program di sekolah atau penyampaian orangtua ke anak. Kesadaran akan kesehatan mental perlu dibangun sejak masih dini untuk mengurangi dampak dari kenaikan prevalensi gangguan mental di dunia. 


\section{U C A P A N T ER I MAKASIH}

Terimakasih kepada Ibu Atika Dian Ariana, S.Psi., M.Sc. selaku dosen pembimbing penulis, kepada Ibu Ika Yuniar Cahyanti, M.Psi., Bapak Danny Arfensia Sanjaya, S.Psi dan Bapak Nido Dipo Wardana, S.Psi selaku professional Judgement untuk alat ukur dalam penelitian ini, kepada Bapak Jonathan Soebiantoro yang telah memberikan izin untuk penulis bisa menggunakan alat ukurnya dalam penelitian ini, kepada kedua orangtua dan seluruh keluarga penulis yang senantiasa memberikan dukungan terbaiknya sehingga penulis bisa menyelesaikan jurnal ini, dan tidak lupa kepada temanteman penulis yang selalu ada untuk mendukung dan menemani penulis hingga akhirnya penelitian ini bisa diselesaikan.

\section{DEKLARASI POTENSI TERJADINYA KONFLIK KEPENTINGAN}

Novia Kartikasari dan Atika Dian Ariana tidak bekerja, menjadi konsultan, memiliki saham, atau menerima dana dari perusahaan atau organisasi mana pun yang akan mengambil untung dari naskah ini, dan telah mengungkapkan bahwa ia tidak memiliki afiliasi selain yang telah disebut di atas.

\section{PUSTAKA ACUAN}

Afifah, K. A. (2016). Literasi Kesehatan Mental pada Tenaga Kesehatan. Surakarta: Universitas Muhammadiyah Surakarta.

Ajzen, I. (1991). The Theory of Planned Behavior. Organizational Behavior and Human Decision Processes $50,179-211$.

Arnett, J. J., Žukauskienė, R., \& Sugimura, K. (2014). The new life stage of emerging adulthood at ages 18-29 years: implications for mental health. Lancet Psychiatry , 1, 569-76.

Cheng, H. L., Wang, C., McDermott, R. C., Kridel, M., \& Rislin, J. L. (2018). Self-Stigma, Mental Health Literacy, and Attitudes Toward Seeking Psychological Help. Journal of Counseling \& Development , 96, 64-74. DOI: 10.1002/jcad.12178.

Crowe, A., Mullen, P. R., \& Littlewood, K. (2018). Self-Stigma, Mental Health Literacy and Health Outcomes in Integrated Care. Journal of Counseling \& Development, 96, 267-277. DOI: 10.1002/jcad.12201.

Evans-Lacko, S., Little, K., Meltzer, H., Rose, D., Rhydderch, D., Henderson, C., et al. (2010). Development and Psychometric Properties of the Mental Health Knowledge Schedule. The Canadian Journal of Psychiatry , 55(7), 440-448.

Hammer, J. H., \& Spiker, D. A. (2018). Dimensionality, Reliability, and Predictive Evidence of Validity for Three Help Seeking Intention Instruments: ISCI, GHSQ, and MHSIS. Journal of Counseling Psychology , 65, 394-401. DOI: 10.1037/cou0000256.

Hogg, M. A., \& Vaughan, G. M. (2011). Social Psychology 6th Edition. England: Pearson Education Limited.

Ikatan Psikolog Klinis Indonesia. (2018, November 1). Statistik Waktu Nyata Jumlah Psikolog Klinis Anggota IPK Indonesia. Retrieved februari 15, 2019, from Ikatan Psikolog Klinis Indonesia: https://ipkindonesia.or.id/informasi-ipk-indonesia/2018/11/statistik-waktu-nyata-datakeanggotaan-ipk-indonesia/ 
Kementerian Kesehatan Republik Indonesia. (2013). Riset Kesehatan Dasar (RISKESDAS). Jakarta: Balitbang.

Kementerian Kesehatan Republik Indonesia. (2018, November 02). Potret Sehat Indonesia dari Riskesdas 2018. Retrieved Januari 12, 2019, from Kementerian Kesehatan Republik Indonesia: http://www.depkes.go.id/article/view/18110200003/potret-sehat-indonesia-dari-riskesdas2018.html

Marchira, C. R., Supriyanto, I., Subandi, Soewadi, \& Good, B. J. (2016). The association between duration of untreated psychosis in first psychotic episode patients and help seeking behaviors in Jogjakarta, Indonesia. International Journal of Culture and Mental Health , 9(2), 120-126. http://dx.doi.org/10.1080/17542863.2015.1103276.

Marthoenis, M., Aichberger, M. C., \& Schouler-Ocak, M. (2016). Patterns and Determinants of Treatment Seeking among Previously Untreated Psychotic Patients in Aceh Province. Scientifica , 1-7. http://dx.doi.org/10.1155/2016/9136079.

McBain, R., Salhi, C., Morris, J. E., Salomon, J. A., \& Betancourt, T. S. (2012). Disease burden and mental health system capacity: WHO Atlas study of 117 low- and middle-income countries. The British Journal of Psychiatry , 201, 444-450. doi: 10.1192/bjp.bp.112.112318.

Mitchell, C. (2017). Mental health help-seeking behaviours in young adults. British Journal of General Practice , 8-9, DOI: 10.3399/bjgp17X688453.

Pheh, K., Anna-Ong, W., Low, S., Tan, C., \& Kok, J. (2018). The Malay Version of the Mental Health Knowledge Schedule: A Preliminary Study. MJP Online Entry , 1-5.

Pheko, M. M., Chilisa, R., Balogun, S. K., \& Kgathi, C. (2013). Predicting Intentions to Seek Psychological Help Among Botswana University Students: The Role of Stigma and Help-Seeking Attitudes. SAGE Journals , 1-11. DOI: 10.1177/2158244013494655.

Rafal, G., Gatto, A., \& Debate, R. D. (2018). Mental health literacy, stigma, and help-seeking behaviors among male college students. Journal of American College Health , DOI:10.1080/07448481.2018.1434780.

Reavley, J. N., \& Jorm, A. F. (2011). National Survey of Mental Health Literacy and Stigma. Department of Health and Aging: Canberra.

Rickwood, D., Thomas, K., \& Bradford, S. (2012). Help-seeking measures in mental health: a rapid review. New South Wales: Sax Institute.

Soebiantoro, J. (2017). Pengaruh Edukasi Kesehatan Mental Intensif Terhadap Stigma pada Pengguna Layanan Kesehatan Mental. INSAN Jurnal Psikologi dan Kesehatan Mental , 2(1), 1-21. DOIi: 10.20473/jpkm.v2i12017.1-21.

Thornicroft, G., Rose, D., Kassam, A., \& Sartorius, N. (2007). Stigma: ignorance prejudice or discrimination? British Journal of Psychiatry , 190, 192-3. doi: 10.1192/ bjp.bp.106.025791.

Vogel, D. L., Shechtman, Z., \& Wade, N. G. (2010). The Role of Public and Self-Stigma in Predicting Attitudes Toward Group Counseling. The Counseling Psychologist , 38(7), 904-922. DOI: 10.1177/0011000010368297.

Vogel, D. L., Wade, N. G., \& Haake, S. (2006). Measuring the Self-Stigma Associated With Seeking 
Psychological Help. Journal of Counseling Psychology , 53(3), 325-337. DOI: 10.1037/00220167.53.3.325.

Watson, A. C., Corrigan, P., Larson, J. E., \& Sells, M. (2007). Self-Stigma in People With Mental Illness. Schizophrenia Bulletin , 33(6), 1312-1318. doi:10.1093/schbul/sbl076.

Whiteford, H. A., Degenhardt, L., Rehm, J., Baxter, A. J., Ferrari, A. J., Erskine, H. E., et al. (2013). Global burden of disease attributable to mental and substance use disorders: findings from the Global Burden of Disease Study 2010. Lancet , 1-12. http://dx.doi.org/10.1016/S01406736(13)61611-6.

WHO. (2001). The World Mental Health 2001: Mental Health: New Understanding, New Hope. Geneva, Switzerland: WHO Library Cataloguing in Publication Data 